\title{
How important is it to identify avoidable hospital readmissions with certainty?
}

\author{
Norbert Goldfield MD
}

See related research article by van Walraven and colleagues at www.cmaj.ca/cgi/doi/10.1503/cmaj.101860

Competing interests: None declared.

This article was solicited and has not been peer reviewed.

Correspondence to: Dr. Norbert Goldfield, nigoldfield@mmm.com

CMAJ 2011. DOI:10.1503 /cmaj.110448
$\mathrm{M}$ any policy-makers believe that if we cannot reduce hospital readmissions, we cannot improve the health care system. ${ }^{1}$ In this issue, van Walraven and colleagues ${ }^{2}$ expertly summarize the relevant research on identifying avoidable readmissions.

However, I find the premise of their article problematic. The authors say, "Readmissions to hospital are increasingly being used as an indicator of quality of care. However, this approach is valid only when we know what proportion of readmissions are avoidable." With expert clinical judgment and by identifying excess readmissions, we can know the approximate proportion of readmissions that are preventable. ${ }^{3}$ In addition, well-done observational and randomized studies have clearly shown that the proportion of readmissions can be reduced. ${ }^{4,5}$ If we combine this knowledge with a comparison of readmission rates, we can use differences in readmission rates among institutions and health care professionals to improve quality of care, for public reporting and for appropriate payment incentives, without knowing precisely how many readmissions are avoidable.

Van Walraven and colleagues' focus on identifying clinically significant adverse events as the causative variable of hospital readmissions overlooks the key reason why a relentless focus on readmissions is critical to improving the overall health care system. Researchers assessing avoidable readmissions often restrict themselves to examining clinical causes. This means they focus on only some of the causes of preventable readmissions.

\section{- KEY POINTS}

- Readmissions to hospital can occur for clinical, socioeconomic and administrative reasons.

- Randomized trials show that readmissions can be reduced.

- We know today the approximate percentage of readmissions that are potentially preventable.

- Given approximate rates, policy-makers can use confidential feedback, public reporting and payment incentives to reduce readmissions.
A randomized clinical trial has shown that readmissions to hospital occur not just for clinical reasons. ${ }^{6}$ They are often the result of deficiencies in coordination and communication within the health care system, such as failure to ensure that a patient has a follow-up visit scheduled with his or her primary care physician at the time of discharge. The entire health care team needs to work together to reduce readmissions resulting from nonclinical causes. Whereas the causes of preventable hospital complications (e.g., infected central lines) can be ascertained using clinical criteria, the evaluation of preventable readmissions must take into account the impact of administrative and socioeconomic, as well as clinical, issues.

We should be debating two fundamental issues pertaining to preventable readmissions: the methods used to identify those that are potentially preventable and the policy levers we should consider as incentives for providers to reduce the proportion of preventable readmissions. There is a debate in the United States about the meaning of the words "preventable" and "avoidable." The National Committee for Quality Assurance has announced a draft allcause approach that makes the strange assertion that all readmissions are potentially preventable. ${ }^{7}$ The National Quality Forum has also certified a measure developed by UnitedHealthcare, the largest insurance company in the United States, that considers virtually all readmissions to be potentially preventable. ${ }^{8}$ As a researcher, I find myself somewhere between this patently problematic approach that has been developed and the approach used by van Walraven and colleagues, which asserts that we need to know a great deal more about which readmissions are potentially preventable.

As the co-developer of the method that uses claims data, I disagree with the assertion by van Walraven that, "given the large variation in the proportion of avoidable readmissions between studies using primary data, 'avoidability' cannot accurately be inferred based on diagnostic codes 
for the index admission and the readmission. Instead, it needs to be determined through a peer-review process in which readmissions are classified as avoidable or not based on expert opinion." The method based on claims data uses several other variables that are present on a claims form in addition to diagnoses. The method should be tested for validity and reliability, as should any attempt to identify potentially preventable readmissions to hospital. Relying on peer review for evaluating readmissions is not practical. Nor is it appropriate, given the variability that is known to exist among opinions expressed by peer reviewers in research about quality of care. Peer review becomes even more problematic given that preventable readmissions have many causes that extend beyond adverse clinical events.

Whereas peer review may not be critical to validating the causes of readmission, there is no question that an institution must be able to replicate the method used to assess readmissions if we expect that institution to reduce readmissions in a continuous manner to improve quality. For example, the method used by the Center for Medicare and Medicaid Services cannot be replicated by institutions because it relies on information that the institution does not have access to, such as that on prior admissions to hospital (which often were not the same hospital) or outpatient care (which is typically provided in community settings not linked electronically to the hospital's medical record system). ${ }^{9}$

Once we have identified an institution's preventable readmissions, we need to be able to compare its rate of such readmissions with rates in similar institutions. The approach used in the recently passed health reform legislation in the United States consists of comparing rates of preventable readmissions and providing a financial incentive when there are significant differences between rates. Thus, the focus is on lowering readmission rates in those institutions that are observed empirically to have higher than expected risk-adjusted readmission rates.

Public reporting and payment incentives to reduce readmissions have been implemented in several states. Payment incentives, however, need to be fair to hospitals and to clinicians. A number of private insurers advocate simply not paying any of the cost of the readmission, whether it was preventable or not, instead of providing a modest incentive to hospitals to reduce those that are preventable. ${ }^{10}$
Hospital readmissions represent a microcosm of today's complex and increasingly expensive medical care system. They exemplify the many challenging and interacting clinical and socioeconomic forces that result in a high rate. Van Walraven and coauthors have summarized well the literature indicating that we don't know with certainty the proportion of readmissions that are clinically preventable. But unlike van Walraven and colleagues or the National Committee for Quality Assurance and National Quality Forum, I am comfortable, as a practicing internist serving a lower socioeconomic patient population, with knowing that, by identifying excess readmissions using reproducible methods, we can know approximately what proportion of readmissions are preventable. As long as the health care team can replicate this approximate measure themselves and a modest payment incentive is applied, I am confident that we can improve performance on this all-important outcome measure.

\section{References}

1. Abelson R. Hospitals pays for cutting costly readmissions. New York Times 2009 May 8. Sect. B:1. Available: www.nytimes.com /2009/05/09/business/09relapse.html?pagewanted=all (accessed 2011 Mar. 7).

2. van Walraven C, Bennett C, Jennings A, et al. Proportion of hospital readmissions deemed avoidable: a systematic review. CMAJ 2011;183:E391-402

3. Goldfield NI, McCullough EC, Hughes JS, et al. Identifying potentially preventable readmissions. Health Care Financ Rev 2008;30:75-91

4. Giordano A, Scalvini S, Zanelli E, et al. Multicenter randomised trial on home-based telemanagement to prevent hospital readmission of patients with chronic heart failure. Int J Cardiol 2009;131:192-9.

5. BOOSTing Care Transitions Resource Room Project Team. Project boost. Philadelphia (PA): Society of Hospital Medicine; 2008. Available: www.hospitalmedicine.org/ResourceRoomRedesign /RR_CareTransitions/html_CC/project_boost_background.cfm (accessed 2011 Mar. 7).

6. Naylor MD, Brooten D, Campbell R, et al. Comprehensive discharge planning and home follow-up of hospitalized elders. JAMA 1999;281:613-20.

7. NCQA. Proposed new measure for HEDIS 2011: plan all-cause readmissions. Washington (DC): National Committee for Quality Assurance; 2011. Available: www.ncqa.org/Portals/0/Public Comment/HEDIS\%202011/Plan\%20All-Cause\%20Readmissions .pdf (accessed 2011 Mar. 7)

8. Healthcare Economics - Medical Informatics. PacifiCare inpatient hospital readmission index methodology. Salt Lake City (UT): UnitedHealthcare; 2007. Available: www.uhc.com/live /uhc_com/Assets/Documents/UnitedHealth\%20Group\%2030-day \%20All-Cause\%20Readmission.pdf (accessed 2011 Mar. 7).

9. Roadmap for quality measurement in the traditional medicare feefor-service program. Baltimore (MD): Centers for MediCare \& MediCaid services. Available: www.cms.gov/QualityInitiatives GenInfo/downloads/QualityMeasurementRoadmap_OEA1-16_508 .pdf (accessed 2011 Mar. 7).

10. IHA Bundled Episode Payment Pilot (BEPP): frequently asked questions. Oakland (CA): Integrated Health Care Association; 2010. Available: www.iha.org/pdfs_documents/medical _device/BPPFAQ_June2010.pdf (accessed 2011 Mar. 7).

Affiliation: Norbert Goldfield is with 3M Health Information Systems Inc. in Wallingford, Mass. 